\title{
The Effect of Advection and Accumulation of Downslope Cold Air on Nocturnal Cooling in Basins
}

\author{
By Masayuki Maki* and Toshio Harimaya \\ Department of Geophysics, Faculty of Science, Hokkaido University, \\ Sapporo 060, Japan \\ (Manuscript received 29 July 1987, in revised form 22 April 1988)
}

\begin{abstract}
The effect of advection and accumulation of cold air from surrounding mountain slopes on the nocturnal cooling at the bottom of basins was studied with the use of one-dimensional numerical model. In the model, horizontal advective cooling was parameterized by using the results of heat budget analyses and power law profiles of air temperature. Calculated results show that the nocturnal cooling in the basin, the depth of which is $500 \mathrm{~m}$ for example, is about $15 \%$ (in winter) and about $25 \%$ (in summer) larger than that at flat terrains while it is about $40 \%$ (in winter) and about $90 \%$ (in summer) larger than that at the top of mountains or hills. These excesses of the nocturnal cooling in basins are due to the difference in downward long wave radiation which is caused by the advection and accumulation of cold air inside basins. This effect of cold air accumulation on the nocturnal cooling is remarkable in deep basins. On the other hand, the nocturnal cooling at the foot of a mountain or in valleys is small compared with that in basins. This can be explained by the difference in the amount of cooling due to the advection and accumulation of downslope cold air among those topographies. Calculated results agreed well with observed values.
\end{abstract}

\section{Introduction}

The nocturnal cooling of the earth's surface is dependent on several kinds of factors. The thermal properties of the ground surface such as the heat capacity and the thermal diffusivity affect the surface cooling significantly. For example, the surface temperature drop of fresh snow cover or dry peaty soil is larger than that of wet sands or wet clayey soil. In addition to the above-mentioned factors, heat transfers of the net radiation, sensible and latent heat fluxes also play important roles in nocturnal cooling. The subject of investigation here is essentially the solution of the equation of heat conduction in the soil layer under appropriate initial and boundary conditions. Early researchers solved

* Present affiliation: National Research Center for Disaster Prevention, Tsukuba Science City 305, Japan.

(C) 1988, Meteorological Society of Japan the one-dimensional equation analytically under simple boundary conditions to investigate the relationship between the surface cooling and factors mentioned above (Brunt, 1932; Jaeger, 1945; Knighting, 1950; Groen, 1947; Fleagle, 1950).

Recently several kinds of numerical models for nocturnal boundary layer (NBL) have been proposed. These models can be divided into three groups according to mechanisms of heat transport considered. The first type of model is that proposed by Anfossi et al. (1976) and Klöppel et al. (1978) who considered only long wave radiation. The second is that in which only turbulence is considered (Delage, 1974; Wyngaard, 1975; Zeman, 1979; Sutherland, 1980). The third is that in which both turbulence and long wave radiation are considered (Kondo, 197.1; Yamada, 1979; Nieuwstadt, 1980; Garratt and Brost, 1981). However, all of these models 
focus mainly on the investigation of the NBL over horizontally homogeneous terrains. Nakamura and Magono (1982) made a numerical simulation of the horizontal distribution of the minimum air temperature on the Hokkaido Island using a one-dimensional model which was the third type of model. However, their results did not reproduce well the minimum air temperature in mountainous areas such as valleys or basins. This may be due to ignoring the effect of downslope cold air in mountainous regions. Kondo (1986) investigated nocturnal cooling processes by a two-dimensional numerical model and clarified the role of downslope wind on the temperature field inside a basin.

From observational studies of the minimum air temperature at various places which had been carried out from the standpoint of local climatology, it became clear that extreme coldness of ten occurred in mountainous regions such as basins and valleys or at the foot of mountains (Yoshino, 1975). However, it is still unclear why extreme coldness occurs inside basins, especially in relation to the role of downslope cold air.

Kondo (1982) and Kondo and Yamazawa (1983) pointed out that downward long wave radiation at the bottom of basins or valleys was less than that on plains because of the advection and accumulation of cold air, i.e., the formation of a "cold air lake". Brunt's results (1932) show that the surface temperature drop during a clear calm night is in proportion to the net radiation. As the amount of net radiation is dependent on the downward long wave radiation, the surface cooling is likely to be large at the place where the amount of downward long wave radiation is small. In order to verify this proposition, observational studies were carried out in the Akaigawa Basin of Hokkaido, Japan (Harimaya et al., 1985; Maki et al., 1986). Maki et al. (1986) confirmed the existence of cold air advection from the surrounding mountain slopes. They showed from the heat budget analyses that about $80 \%$ of the observed cooling of the whole air layer inside the basin on a clear calm night was attributable to the advection and accumulation of cold air. However, some essential problems remain unsolved. For example, to what extent is the downward long wave radiation decreased by the advection and accumulation of cold air? And, as a result, to what extent does the surface temperature drop increase? The purpose of this paper is to study the effect of the advection and accumulation of cold air on nocturnal cooling by means of a one-dimensional numerical model.

\section{Observed nocturnal cooling at clear nights}

For the preliminary analysis, the dependence of nocturnal cooling on the topography was studied by using AMeDAS (Automated Meteorological Data Acquisition System) data of Hokkaido, Japan from 1978 to 1982, which were recorded at time intervals of one hour. Each of the observation sites $(=162)$ was classified roughly into one of three groups according to its topographical feature, i.e., mountainous area, plain area, and seaside area. The classification of AMeDAS points is the same that Maki and Harimaya (1984) used in the principal component analysis of nocturnal cooling. Fig. 1 shows the relationship between the extreme nocturnal cooling and the mean wind speed at each topography in three seasons (winter, summer, and spring and autumn). Nocturnal cooling was defined as the temperature drop from sunset to the time when the minimum temperature was recorded. And the maximum nocturnal cooling in each month during the five-year period was referred to as the extreme nocturnal cooling. The mean wind speed is the averaged value from sunset to the time when minimum air temperature was recorded and it was taken at a height of about $10 \mathrm{~m}$. Despite the scattering found in the observed values in Fig. 1, which may be due to the rough classification of seasons as well as topographies, it is clear that the large extreme nocturnal cooling was observed when the mean wind speed was small. In addition, it became evident that the wind speed for mountainous or plain areas is generally smaller than that for seaside areas. It was also shown that the extreme cooling in the winter season is larger than that in the summer season for each of the topographies.

In addition to the general dependence of wind speed on the extreme cooling mentioned above, 

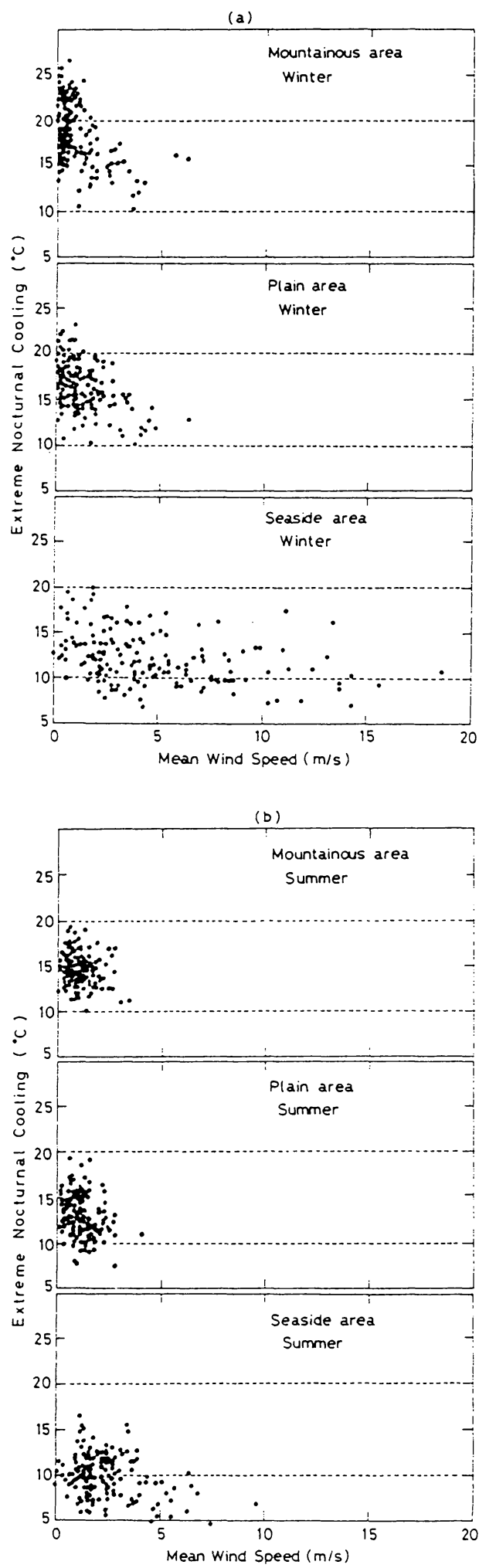

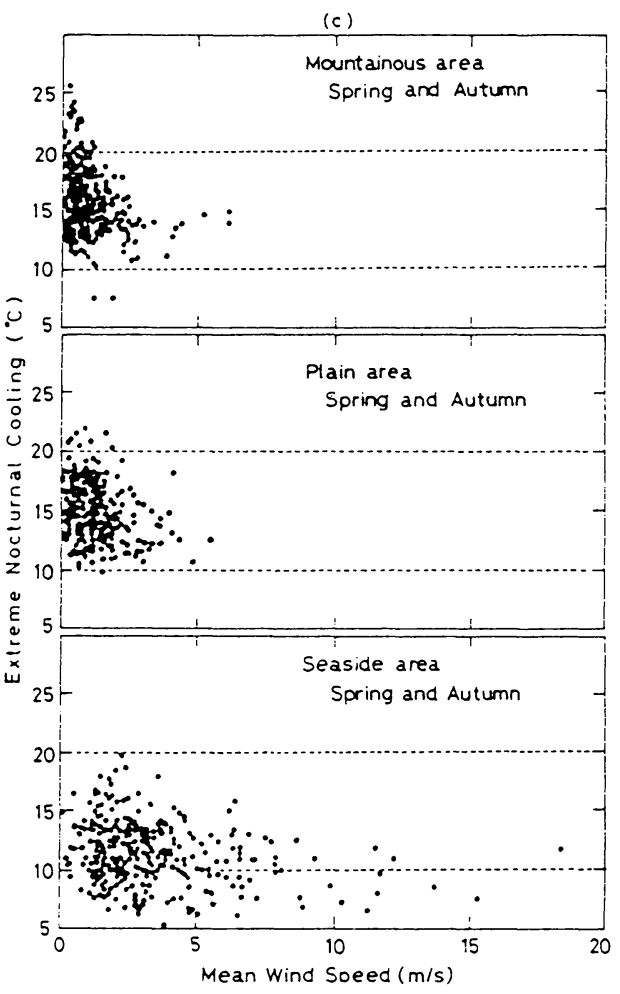

Fig. 1. Relationships between the extreme nocturnal cooling and the mean wind speed in winter (December, January, and February) (a), summer (June, July, and August) (b), and spring (March, April, and May) and autumn seasons (September, October, and November) (c). Data were selected out from AMeDAS data in Hokkaido, Japan during five years.

it must be noted that there is a difference in the extreme cooling at each topography even though the wind conditions are the same. In order to study this difference in detail, data taken when the wind speed was less than $1 \mathrm{~ms}^{-1}$ at each topography were selected from the plotted data in Fig. 1. This condition enabled us to neglect the effect of the amount of sensible heat flux on the extreme nocturnal cooling and to study the dependence of the extreme nocturnal cooling on the topographic features.

The extreme nocturnal cooling data for each season and each topography, which were selected under the condition mentioned above, are shown in Fig. 2. Their statistics are listed in Table 1. Although the linear regression lines shown in Fig. 2 may not have any physical meaning, they will 


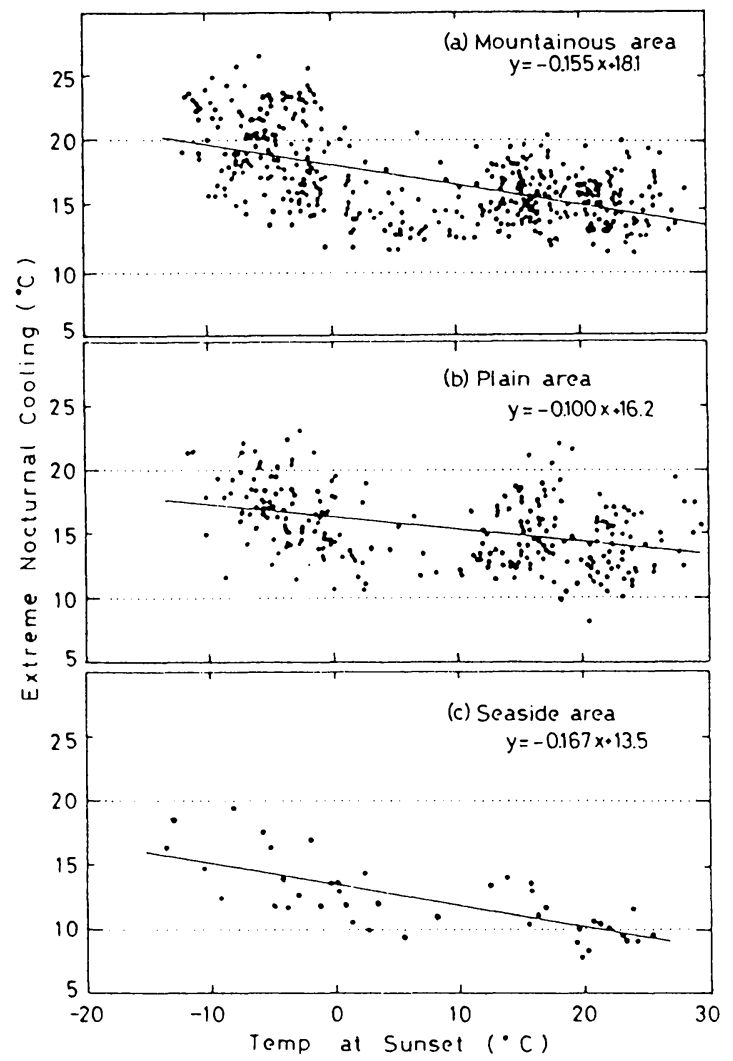

Fig. 2. Relationships between the extreme nocturnal cooling and the temperature at sunset under calm wind conditions. The line in each figure represents the linear regression line obtained by the least squares method. be useful in discussing the dependence of the extreme nocturnal cooling on topography and its seasonal change under calm wind conditions. It can be seen that the extreme nocturnal cooling which is apt to increase in the winter season is larger in the mountainous area than on the plain and seaside areas. According to Table 1, the maximum values of the extreme nocturnal cooling in the mountainous area, plain area, and seaside area, all of which were recorded in winter season, are $26.5^{\circ} \mathrm{C}, 23.2^{\circ} \mathrm{C}$, and $19.4^{\circ} \mathrm{C}$ respectively. The difference in the mean values of the extreme nocturnal cooling is about $2^{\circ} \mathrm{C}$ between the mountainous area and the plain area and about $5^{\circ} \mathrm{C}$ between the mountainous area and the seaside area. These differences in mean values among three topographies are statistically significant with $95 \%$ reliability. These statistics will be used later to examine the validity of calculation results. According to Table 1, the probability (case/total) of a wind speed less than $1 \mathrm{~ms}^{-1}$ is larger in the mountainous area than at the other topographies. This can be explained by the effect of the topography on the wind field in the mountainous area, i.e., "blocking effect".

It is also interesting that the plotted data in Fig. 2 are not distributed uniformly and are deficient within the range from about $0^{\circ} \mathrm{C}$ to $10^{\circ} \mathrm{C}$ for the temperature at sunset. In other words, extreme coldness is rarely observed within

Table 1. Statistics (maximum value, mean value, and standard deviation) of the extreme nocturnal cooling under calm wind conditions. total : total number of data which were plotted in Fig. 1. case : the number of data which satisfied the calm wind condition (wind speed is less than $\left.1 \mathrm{~ms}^{-1}\right)$.

\begin{tabular}{|c|c|c|c|c|c|c|}
\hline season & topography & case/total & $\begin{array}{c}\text { probability } \\
(\%)\end{array}$ & $\max _{\left({ }^{\circ} \mathrm{C}\right)}$ & $\underset{\left({ }^{\circ} \mathrm{C}\right)}{\operatorname{mean}}$ & $\begin{array}{c}\text { standard } \\
\text { deviation }\left({ }^{\circ} \mathrm{C}\right)\end{array}$ \\
\hline \multirow{3}{*}{ winter } & $M$ & $126 / 177$ & 71.2 & 26.5 & 19.5 & 2.9 \\
\hline & $P$ & $75 / 147$ & 51.0 & 23.2 & 17.2 & 2.7 \\
\hline & $\mathrm{S}$ & $14 / 162$ & 8.6 & 19.4 & 14.5 & 2.8 \\
\hline \multirow{3}{*}{ summer } & $\mathrm{M}$ & $91 / 177$ & 51.4 & 19.3 & 14.8 & 1.7 \\
\hline & $P$ & $61 / 147$ & 41.5 & 19.4 & 13.3 & 2.2 \\
\hline & $\mathrm{S}$ & $12 / 162$ & 7.4 & 11.6 & 9.8 & 1.0 \\
\hline \multirow{3}{*}{$\begin{array}{l}\text { spring, } \\
\text { autumn }\end{array}$} & $\mathrm{M}$ & $232 / 354$ & 65.5 & 25.6 & 16.0 & 2.7 \\
\hline & $\mathrm{P}$ & $130 / 294$ & 44.2 & 22.0 & 15.1 & 2.5 \\
\hline & $\mathrm{S}$ & $17 / 324$ & 5.2 & 16.4 & 12.1 & 2.1 \\
\hline
\end{tabular}

M : Mountainous area, $\mathrm{P}$ : Plain area, $\mathrm{S}:$ Seaside area 
such a temperature range. This may be explained by the effect of latent heat release, because the temperature at the ground surface falls below $0^{\circ} \mathrm{C}$ during the cooling process and a water phase change occurs.

\section{Numerical model}

\subsection{Assumptions}

The following assumptions were used in the present study:

(1) The vertical profile of the potential temperature of the air layer at each instant can be expressed by a power law profile.

(2) The heat exchange between the air layer inside a basin and air layer outside a basin can be neglected except for that via radiation.

(3) The effect of latent heat release on the temperature field is not considered.

Although temperature profiles in the surface layer over horizontally flat terrains can be expressed by a non-dimensional sheal function which is a function of the stability parameter, functional forms of temperature profiles over complex terrains are not available. Therefore, we will use assumption (1) for simplicity. Assumption (2) may be valid because we will study the mechanism of nocturnal cooling under weak wind conditions. Assumption (3) does not mean that the effect of latent heat on the nocturnal cooling is unimportant; on the contrary, its effect cannot be disregarded when realistic nocturnal cooling is considered. However, the main purpose of this study is to investigate the effect of advection and the accumulation of cold air on the nocturnal cooling. Thus, we use the assumption (3).

\subsection{Basic equations}

The equation for conduction in the soil layer is

$$
\frac{\partial T_{g}}{\partial t}=\kappa_{g} \frac{\partial^{2} T_{g}}{\partial z^{2}}
$$

where $T_{g}$ is the ground temperature at the depth of $z$ and $\kappa_{g}$ the thermal diffusivity of the soil layer, being assumed to be constant with respect to the depth. $\kappa_{g}$ is written as

$$
\kappa_{g}=\frac{\lambda_{g}}{\rho_{g} C_{g}},
$$

where $\lambda_{g}$ is the thermal conductivity, $\rho_{g}$ the soil density and $C_{g}$ the specific heat of the soil.

The time change for the air temperature is represented formally by

$$
\left(\frac{\partial \theta}{\partial t}\right)_{a}=\left(\frac{\partial \theta}{\partial t}\right)_{h}+\left(\frac{\partial \theta}{\partial t}\right)_{r}+\delta\left(\frac{\partial \theta}{\partial t}\right)_{x},
$$

where,

$(\partial \theta / \partial t)_{a}:$ actual heating rate,

$(\partial \theta / \partial t)_{h}$ : heating rate due to the convergence of sensible heat flux,

$(\partial \theta / \partial t)_{r}$ : heating rate due to the convergence of long wave radiation,

$(\partial \theta / \partial t)_{x}$ : heating rate due to the advection and accumulation of cold air.

The coefficient $\delta$ in Eq. (3) must be set to 0 when the time change for the air temperature over flat terrains is considered, while $\delta=1$ when the nocturnal cooling in a basin is the object of investigation. As will be mentioned later, $(\partial \theta / \partial t)_{x}$ is taken into account by assuming a power law profile of potential temperature and by using the observational results of vertically integrated heat budget analyses.

$(\partial \theta / \partial t)_{h}$ and $(\partial \theta / \partial t)_{r}$ can be expressed as follows.

$$
\begin{aligned}
& \left(\frac{\partial \theta}{\partial t}\right)_{h}=\frac{\partial}{\partial z}\left(K_{h} \frac{\partial \theta}{\partial z}\right), \\
& \left(\frac{\partial \theta}{\partial t}\right)_{r}=-\frac{1}{\rho C_{p}} \frac{\partial}{\partial z}\left(L^{\uparrow}(z)-L^{\downarrow}(z)\right),
\end{aligned}
$$

where $K_{h}$ is the eddy diffusivity for heat, $\rho$ the air density, $C_{p}$ the specific heat of air at constant pressure, $L^{\dagger}(z)$ the upward long wave radiation and $L^{\downarrow}(z)$ the downward long wave radiation at height $z$. According to Sasamori (1968) $L^{\downarrow}(z)$ and $L^{\dagger}(z)$ can be represented as follows,

$$
\begin{aligned}
L^{\downarrow}(z)= & 4 \sigma \int_{T\left(z_{k}\right)}^{T(z)} \overline{A_{0}}\left\{w\left(T^{\prime}\right)-w[T(z)]\right\} T^{\prime 3} d T^{\prime} \\
& +4 \sigma T^{4}\left(z_{k}\right) \overline{\bar{A}}\left\{w\left[T\left(z_{k}\right)\right]\right. \\
& \left.-w[T(z)], T\left(z_{k}\right)\right\}, \\
L^{\dagger}(z)= & \sigma T^{4}(0)+4 \sigma \int_{T(0)}^{T(z)} \overline{A_{0}} \\
& \cdot\left\{w[T(z)]-w\left(T^{\prime}\right), T^{\prime}\right\} T^{\prime 3} d T^{\prime}, \quad(7)
\end{aligned}
$$


where $\sigma$ is the Stefan-Boltzmann constant $\left(=5.6710^{-8} \mathrm{~W} \mathrm{~m}^{-2} \mathrm{~K}^{-4}\right)$ and $\overline{A_{0}}$ and $\overline{\bar{A}}$ denote mean absorptivities which are given empirically from Yamamoto's radiation chart (Yamamoto, 1952). The upper limit of the integration $z_{k}$ is the depth of the atmospheric layer required to calculate the downward long wave radiation, which is taken to be $15 \mathrm{~km} . w$ is the effective path length which represents the amount of absorbing gases for radiation. Considering the effect of atmospheric pressure, $w$ can be written as

$$
w=\frac{1}{g} \int_{p}^{p_{0}} q\left(\frac{p}{p_{s}}\right) d p,
$$

where $g$ is the gravitational acceleration, $p_{0}$ the pressure at the ground surface, $p_{s}$ the standard. pressure, and $q$ the mixing ratio of absorbing gas. In this study $p_{0}=p_{s}=1000 \mathrm{mb}$ and we consider water vapor and carbon dioxide to be absorbing gases.

$K_{h}$ above the surface layer is assumed to take the following form suggested by O'Brien (1970):

$$
\begin{aligned}
K_{h}(z)= & K_{h}(h)+\frac{(h-z)^{2}}{\left(h-h_{s}\right)^{2}}\left\{K_{h}\left(h_{s}\right)-K_{h}(h)\right. \\
& +\left(z-h_{s}\right)\left[\left.\frac{\partial K_{h}}{\partial z}\right|_{z=h_{s}}\right. \\
& \left.\left.+\frac{2\left(K_{h}\left(h_{s}\right)-K_{h}(h)\right)}{h-h_{s}}\right]\right\}, \quad h_{s} \leqq z \leqq h,
\end{aligned}
$$

where $h$ is the height of the nocturnal boundary layer and $h_{s}$ the height of the surface layer. Blackadar and Tennekes (1968) found the relation

$$
h_{s}=0.04 h \text {. }
$$

in a neutrally stratified layer. In this paper, we set $h_{s}=10 \mathrm{~m}$ for simplicity. On the other hand, $K_{h}$ in the surface layer $\left(0 \leqq z \leqq h_{s}\right)$ is of the form :

$$
K_{h}(z)=\frac{\kappa u_{* 0} z}{\phi_{h}(\zeta)}=\frac{\kappa u_{* 0} z}{\alpha \phi_{m}(\zeta)}
$$

where $\kappa$ is the von Karman's constant $(=0.4), u_{* 0}$ the friction velocity at the ground surface, $\phi_{h}(\zeta)$ the non-dimensional temperature gradient, $\phi_{m}(\zeta)$ the non-dimensional shear. And $\alpha$ is defined by

$$
\alpha=\frac{K_{m}}{K_{h}},
$$

where $K_{m}$ is the eddy diffusivity for momentum. Adopting the modified KEYPS formula (Yamamoto, 1975, Eq. 45) to the shear function, we have

$$
K_{h}(z)=\frac{\kappa u_{* 0} z}{\alpha\left(9 \zeta+\sqrt{ } 81 \zeta^{2}+1\right)^{1 / 2}}, \quad 0 \leqq z \leqq h_{s}
$$

where $\zeta\left(=z / L_{0}, L_{0}:\right.$ the Monin-Obukhov length) is a dimensionless height. $L_{0}$ is defined as

$$
L_{0}=\frac{u_{* 0}^{3}}{\kappa \frac{g}{\bar{\theta}} \frac{\left|H_{0}\right|}{\rho C_{p}}},
$$

where $H_{0}$ is the sensible heat flux and $\bar{\theta}$ the mean potential temperature near the surface.

If we neglect the pressure gradient force and Coriolis force, wind profiles are given by solving

$$
\frac{\partial u}{\partial t}=\frac{\partial}{\partial z}\left(K_{m} \frac{\partial u}{\partial z}\right)
$$

The heat budget equation at the surface is given by

$$
L_{0}^{\dagger}-L_{0}^{\dagger}=G_{0}+H_{0},
$$

where $G_{0}$ is the soil heat flux, $H_{0}$ the sensible heat flux. The subscript 0 indicates the value at the surface. In deriving Eq. (16) we used the assumption (2) in section 3.1 and assumed that the surface was black body and the solar radiation was zero.

The soil heat flux $G_{0}$, the sensible heat flux $H_{0}$, and the friction velocity $u_{* 0}$ at the surface can be calculated by following equations.

$$
\begin{aligned}
& G_{0}=-\lambda_{8}\left(\frac{\partial T_{g}}{\partial z}\right)_{z=z_{1}}, \\
& H_{0}=-K_{h}\left(\frac{\partial \theta}{\partial z}\right)_{z=z_{1}}, \\
& u_{* 0}=\frac{\kappa u\left(z_{1}\right)}{\ln \frac{z_{1}}{z_{0}}} .
\end{aligned}
$$

Here, $z_{1}$ is a very small height from the ground. 


\subsection{Horizontal advection}

When we consider the nocturnal cooling in basins, the coefficient $\delta$ in Eq. (3) must be 1 . Here we will parameterize this advection term by using the results of heat budget analyses (Maki et al., 1986) and the assumption of power law profiles of potential temperature.

If the advection and accumulation of cold air plays an important role in the nocturnal cooling inside basins, vertical profiles of the potential temperature seem to have peculiar forms which are different from those over horizontally flat terrain. For example, Toritani (1985) clarified the three-layer structure of the air layer inside a basin, those being the lowest thermally stable sub-layer which is under almost calm wind conditions, the middle sub-layer into which cold air penetrates from the surrounding mountain slopes, and the upper, neutrally stratified sub-layer where general wind prevails. On the other hand, in the case of homogeneous terrain, potential temperature profiles in the surface layer are generally expressed by the nondimensional shear function. An alternative expression for the temperature profile is that of the power law profile, i.e.,

$$
\frac{\theta(z, t)-\theta(h, t)}{\theta(h, t)-\theta(0, t)}=-\left(1-\frac{z}{h}\right)^{a(t)}
$$

where $h$ is the inversion height. Yamada (1979) applied this formula to Wangara data and found $a=3$. Fig. 3 shows nondimensional potential temperature profiles which were obtained in two basins, one is the Akaigawa Basin and the other the Moshiri Basin. Data are those taken during calm nights in autumn in the case of Akaigawa and in midwinter in the case of Moshiri. As the time change for the air temperature was large just after sunset, the data at that time were excluded. The value of $a$ in Eq. (20) is found to be 1.8 by using a least squares method. Thus it can be said that a relatively linear profile is characteristic of temperature profiles inside basins. As will be mentioned later, Eq. (20) will be used to parameterize the horizontal advective cooling.

Integrating Eq. (3) from the surface to the top of the atmospheric boundary layer and setting $\delta$ $=1$, we can obtain the following integrated heat
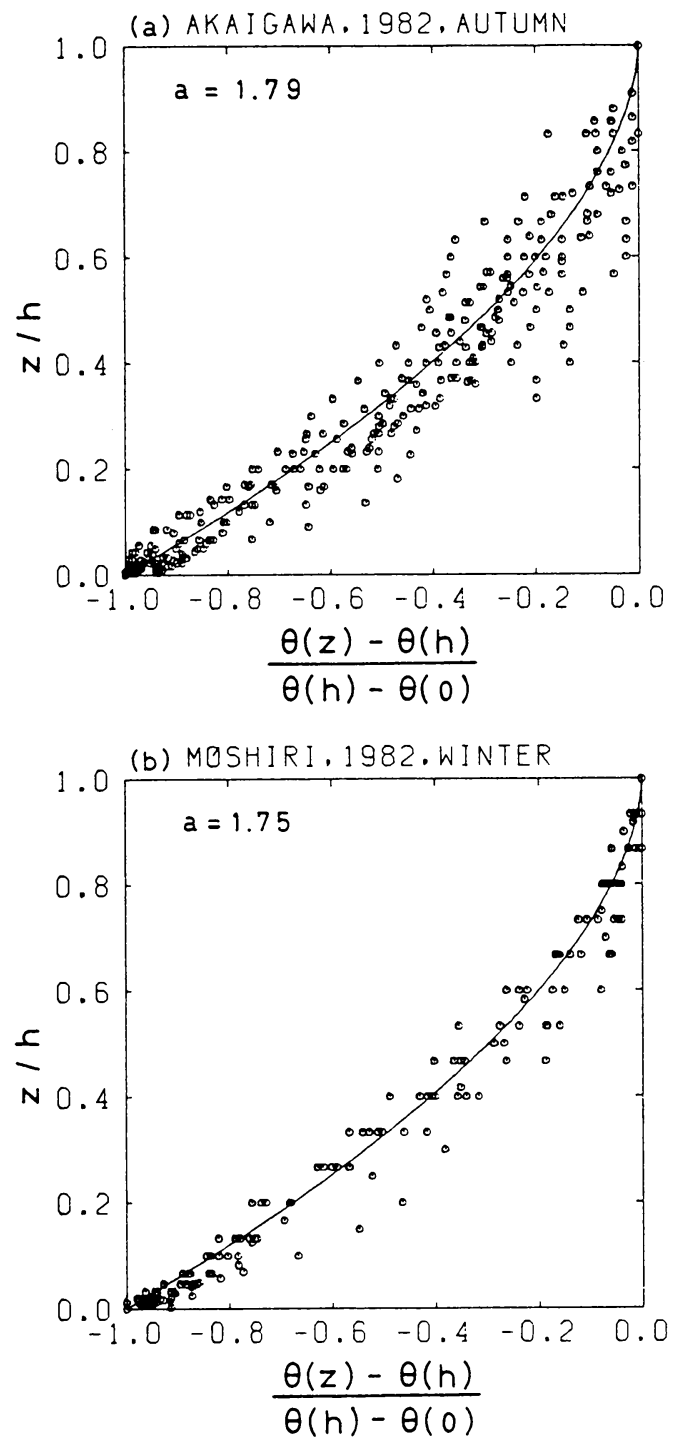

Fig. 3. Air temperature profiles observed at Akaigawa (a) in autumn of 1982 and Moshiri (b) in midwinter of 1982. Akaigawa is a basin which has a bottom of about $5 \mathrm{~km}$ in diameter and is surrounded by mountains of about $250 \mathrm{~m}$ above the bottom of the basin. Moshiri is also a basin which has a bottom of about $2 \mathrm{~km}$ in diameter and is surrounded by mountains of about $200 \mathrm{~m}$ above the bottom. They are located in Hokkaido, Japan.

budget equation for the air column (see Fig. 4):

$$
Q A=Q H+Q R+Q X,
$$

where, 


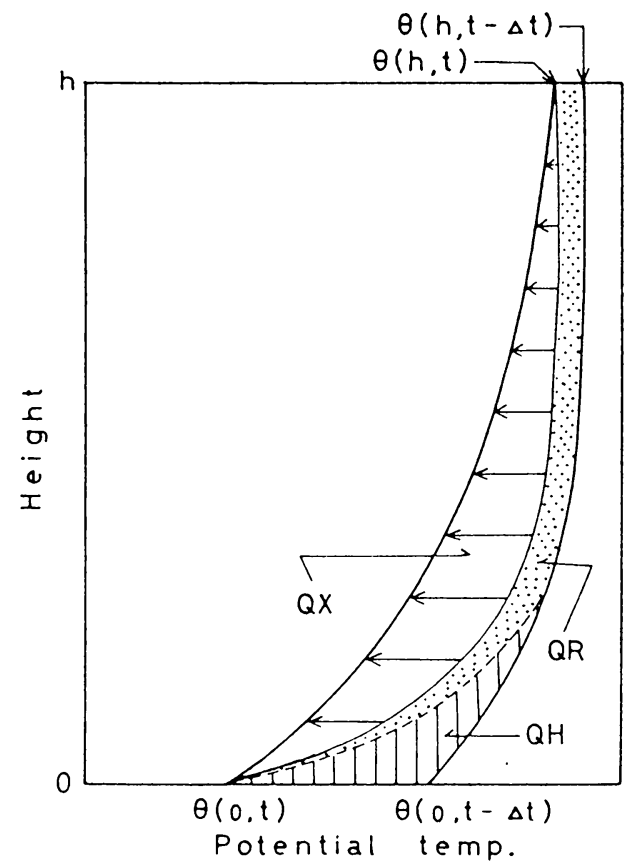

Fig. 4. Schematic picture showing the time change for air temperature profiles inside a basin. Where $Q H$ is the turbulent cooling, $Q R$ the long wave radiative cooling and $Q X$ the horizontal advective cooling.

$$
Q A=\rho C_{p} \int_{0}^{h}\left(\frac{\partial \theta}{\partial t}\right)_{a} d z
$$

$$
\begin{aligned}
Q H & =\rho C_{p} \int_{0}^{h}\left(\frac{\partial \theta}{\partial t}\right)_{h} d z \\
& =\rho C_{p} \int_{0}^{h} \frac{\partial}{\partial z}\left(K_{h} \frac{\partial \theta}{\partial z}\right) d z \approx H_{0}, \\
Q R & =\rho C_{p} \int_{0}^{h}\left(\frac{\partial \theta}{\partial t}\right)_{r} d z \\
& =-\int_{0}^{h} \frac{\partial}{\partial z}\left(L^{\dagger}(z)-L^{\downarrow}(z)\right) d z .
\end{aligned}
$$

In Eq. (23) we assumed that the sensible heat flux vanished at $h$, because gradient of air temperature $\partial \theta / \partial z$ becomes zero at that height. Assuming that profiles of air temperature at any time $t$ are represented by the form of Eq. (20), then $Q A$ can be written as

$$
\begin{aligned}
Q A= & \frac{\rho C_{p}}{\Delta t} \int_{0}^{h}\{\theta(z, t)-\theta(z, t-\Delta t)\} d z \\
= & \frac{\rho C_{p}}{\Delta t}\{\theta(h, t) h-[\theta(h, t)-\theta(0, t)] \\
& \left.\cdot \frac{h}{a(t)+1}-\int_{0}^{h} \theta(z, t-\Delta t) d z\right\} .
\end{aligned}
$$

Substituting Eq. (25) into Eq. (21) and transforming the results in the equation yields

$$
a(t)=\frac{\{\theta(h, t)-\theta(0, t)\} h}{\theta(h, t) h-\int_{0}^{h} \theta(z, t-\Delta t) d z-\frac{(Q H+Q R+Q X) \cdot \Delta t}{\rho C_{p}}}-1 .
$$

Then the temperature profile at a time $t$, i.e., the value of $a(t)$ can be obtained if $Q X$ is given. According to the results of the heat budget analyses (Maki et al., 1986), the ratio of $Q X$ to $Q A$ on a calm night decreased slightly with the lapse of time after sunset. Therefore, we assume that the ratio of $Q X$ to $Q A$ is constant with respect to time as follows.

$$
\frac{Q X}{Q A}=C, \quad(0 \leqq C \leqq 1) .
$$

Thus, $Q X$ can be calculated by

$$
Q X=\frac{C \cdot(Q H+Q R)}{1-C}
$$

In this study, calculations are performed for
$C=0.8, C=0.5$ (the case of mountainous area) and $C=0$ (the case of flat terrains).

\subsection{Numerical aspects}

Partial differential equations such as Eq. (1) and Eq. (4) can be generally solved numerically by using a finite difference approximation. In this study forward-in-time and centered-in-space schemes were used. As for vertical grid levels the following relationship between the grid level $\left(z^{*}\right)$ and the vertical coordinate $(z)$ was used to increase space resolution in the temperature field near the surface:

$$
z^{*}=a_{1} \ln \left(1+b_{1} z\right) .
$$

Here $a_{1}=1, b_{1}=100$ for $z_{b} \leqq z \leqq 0 \mathrm{~m}$ and $a_{1}=1$, $b_{1}=0.5$ for $0 \leqq z \leqq h \mathrm{~m}$. The number of grid 
levels is 20 for atmospheric layers below the height of $h$ and 12 for the soil layers to the depth of $z_{b}$.

Initial conditions of the temperature field are a neutrally stratified layer for the atmospheric layer $(0 \leqq z \leqq h)$ and a uniformly distributed soil temperature from the surface to the depth of $z_{b}$. As for the wind profile, we assumed

$$
u(z)=\frac{u(h) \ln \frac{z}{z_{0}}}{\ln \frac{h}{z_{0}}},
$$

where $z_{0}$ is the surface roughness. For water vapor we assumed that the relative humidity was constant $(=70 \%)$ at each level in the boundary layer.

Boundary conditions at the surface are the heat budget equation (16) and $\theta(0)=T(0)$. For upper boundary condition, we assumed $(\partial \theta / \partial t)=0$ at the height of $h$. For lower boundary condition, we assumed that soil temperature below the depth of $z_{b}$ was constant. The wind speed assumed was $u=1 \mathrm{~ms}^{-1}$ at the height $h$.

In order to calculate the long wave radiation, the air temperature profile and the vertical distribution of absorbing gases in the layer above the NBL are also needed. For profiles of air temperature and water vapor we adopted the model proposed by McClatchey et al. (1972). For the distribution of $\mathrm{CO}_{2}$ we assumed a homogeneous distribution at all levels of concentration of $330 \mathrm{ppm}$.

Surface thermal properties used in calculations were as follows, $\lambda_{g}=0.10\left(\mathrm{Wm}^{-1} \mathrm{~K}^{-1}\right)$, $\kappa_{g}=0.40 \times 10^{-6} \quad\left(\mathrm{~m}^{2} \mathrm{~s}^{-1}\right)$, and $\rho C_{g}=0.25$ $\left(\mathrm{Jm}^{-3} \mathrm{~K}^{-1}\right)$. These values characterize thermal properties of fresh snow cover or dry peaty soil which are suitable for extreme radiative cooling. The other numerical values are as follows; $z_{0}=0.001 \mathrm{~m}, z_{b}=1 \mathrm{~m}, z_{1}=0.5 \mathrm{~m}, \alpha=K_{m} / K_{h}=1 / 1.24$, $h=100,250,500 \mathrm{~m}$, and $C=0.0,0.5,0.8$.

\section{Numerical results}

\subsection{Nocturnal cooling in the case of $L_{0}^{\downarrow}=$ const.}

Before studying the effect of the decrease in $L_{0}^{\downarrow}$ on the surface cooling, we calculated the nocturnal cooling for the case in which $L_{0}^{\downarrow}(t)$ is constant with respect to time. Although this condition may not exist in reality in the strict sense, it can be regarded as approximately that for the nocturnal cooling at the top of a hill or a mountain. That is, in contrast to a condition inside a basin where a deep cold air layer is formed, cooled air is restricted only to the shallow layer close to the surface because cooled air flows down from the top of a mountain. As a result, the decrease in $L_{0}^{\downarrow}$ during the night, which is dependent on the depth and the temperature of the cold air layer, is smaller than that at the bottom of a basin.

The nocturnal cooling at the surface in the case of $L_{0}^{\downarrow}=$ const. is shown in Fig. 5 . Here, the boundary condition for the calculation is the heat budget equation which represents the complete balance between the outgoing net radiation and the soil heat flux. Because of the condition that the air temperature over the surface does not change with time, which is a necessary condition for $L_{0}^{\downarrow}=$ const., sensible heat flux was neglected. According to Fig. 5, nocturnal cooling at the surface is from about $14^{\circ} \mathrm{C}$ to about $20^{\circ} \mathrm{C}$ within the initial temperature range from $25^{\circ} \mathrm{C}$ to $-10^{\circ} \mathrm{C}$ when, for

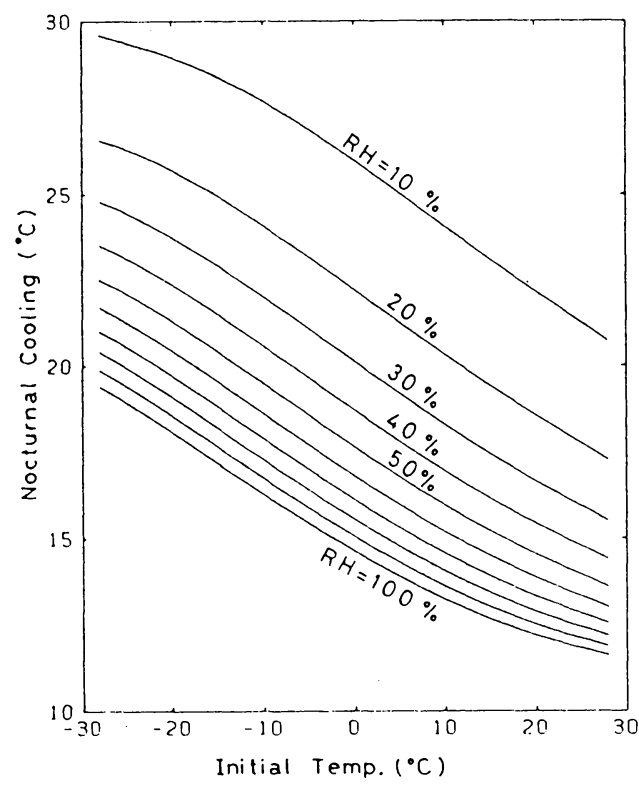

Fig. 5. Calculated nocturnal cooling at the surface under the condition that $L_{i}$ is constant with the lapse of time. $R H$ represents the relative humidity. 
example, the relative humidity at sunset is $50 \%$. These values for the initial temperature and humidity can usually be observed in Hokkaido (see Fig. 2). Hereafter in this paper, for the sake of convenience, we will regard $-10^{\circ} \mathrm{C}$ as the representative initial temperature at sunset in winter and regard $25^{\circ} \mathrm{C}$ as that in summer. It was also noted that the nocturnal cooling on a dry night is larger than that on a wet night.

\subsection{Calculated air temperature profiles}

$L_{0}^{\downarrow}$ decreases with the lapse of time after sunset not only in basins but also over horizontally homogeneous terrain because the air layer over the surfaces of both topographies is cooled. However, as pointed out early in this paper and suggested by Maki et al. (1986), air temperature profiles inside a basin are different from that over a flat terrain because of the existence of downslope cold air. In order to study this difference and the resultant effect on the decrease in $L_{0}^{\downarrow}$, we performed calculations for the case of $C=0.8,0.5$ with initial temperature $-5^{\circ} \mathrm{C}$ and $h=250 \mathrm{~m}$ as an example.

The calculated time change of air temperature profiles over a flat terrain and that for inside a basin are shown in Fig. 6(a) and Fig. 6(b), respectively. In the case of flat terrain, strong cooling due to the divergence of sensible heat flux, that is, the turbulent cooling, is restricted to the lower part of the air layer. The cooling of the upper layer which is due to atmospheric radiative cooling takes on only small values. This calculated time change of the air temperature profiles agrees qualitatively with the profile of the cooling rate observed by Kondo et al. (1978). On the other hand, in the case of a basin where the cooling due to advection and accumulation of cold air plays an important role in the air temperature field inside a basin, cooling extends to the upper part of the layer. Thus, it can be said that the upper part of the air layer inside a basin is colder than that over a flat terrain. The calculated results also show the effect of the parameter $C$ on the temperature profile form. As shown in Fig. 6(b), the larger the parameter $C$ is, the smaller is the curvature of the profile. The exponent $a$ in Eq. (20) is 1.61 at 12 hours after sunset when $C=0.8$, which is in good agreement with the observed value shown in Fig. 3 , while $a=3.60$ when $C=0.5$.

\subsection{Differerence in downward long wave radia- tion between basins and flat terrains}

The difference in the form of the air temperature profiles results in a difference in the downward long wave radiation $L_{0}$. Calculated time changes of $L_{0}^{\downarrow}$ under the same conditions as those in Fig. 6 are shown in Fig. 7(a), where $\Delta L_{0}^{\downarrow}$ is the time change of $L_{0}^{\downarrow}$ after sunset. The results show
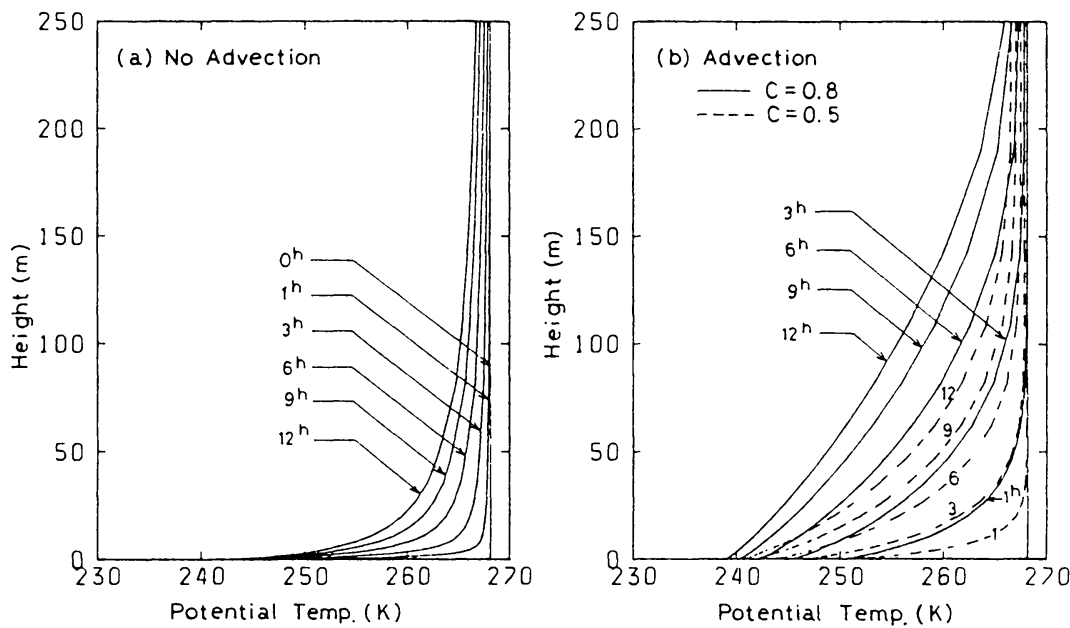

Fig. 6. Calculated time change for air temperature profiles. (a) presents the case of $C=Q X / Q A=0$ (over a flat terrain) and (b) $C=0.8$ (inside a basin) and $C=0.5$ (over the foot of a mountain) respectively. 

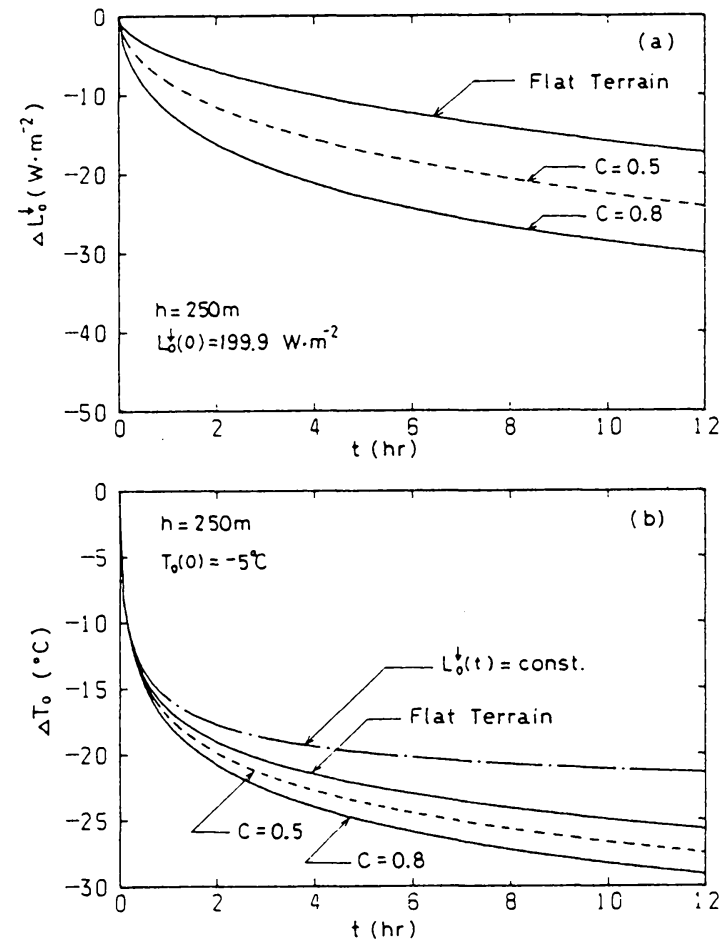

Fig. 7. Calculated time change of $L_{0}^{\dagger}$ (a) and $T_{0}$ (b), where $\Delta L_{0}^{+}$represents the time change in downward long wave radiation and $\Delta T_{0}$ the surface temperature change. Conditions used in calculation are the same as those used in Fig. 6.

that $\Delta L_{0}^{\downarrow}$ changes with the lapse of time according to the time change of air temperature profiles. However, a difference in $\Delta L_{0}^{\downarrow}$ during 12 hours takes place between flat terrain and a basin. $\Delta L_{0}^{\dagger}$ is $-30.1 \mathrm{Wm}^{-2}$ in the case of a basin, while it is $-17.4 \mathrm{Wm}^{-2}$ in the case of flat terrain. This difference in $\Delta L_{0}^{\downarrow}$ causes the difference in the surface temperature between a basin and flat terrain, as shown in Fig. 7(b). According to Fig. 7(b), $\Delta T_{0}$ during 12 hours is $-29.1^{\circ} \mathrm{C}$ in a basin, while it is $-25.7^{\circ} \mathrm{C}$ on flat terrain. In Fig. 7(b), the calculated temperature change in the case of $L_{0}^{\downarrow}=$ const., i.e., the nocturnal cooling at a mountain top,is also shown as a reference. In this case $\Delta T_{0}$ during 12 hours is $-21.4^{\circ} \mathrm{C}$.

It was also noted that $\Delta L_{0}^{\downarrow}$ is dependent on the parameter $C$; the larger the value of $C$, the larger is the decrease in downward long wave radiation.

In addition to the dependence of $\Delta L_{v}^{\downarrow}$ on $C$,

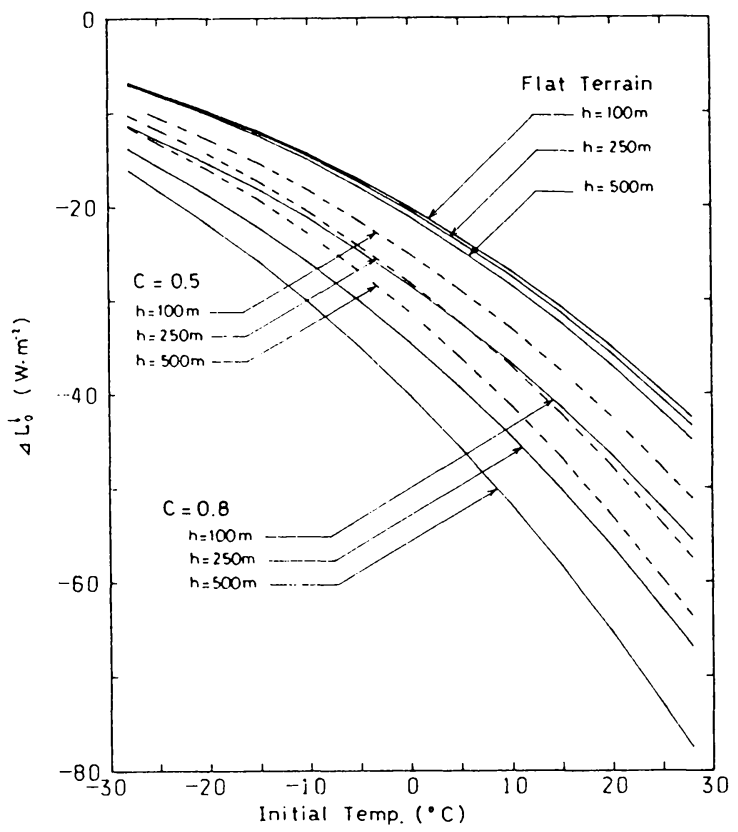

Fig. 8. Change in downward long wave radiation during a night (=12 hours) at flat terrains, basins $(C=0.8)$ and the foot of mountains $(C=0.5)$.

$\Delta L_{0}^{\downarrow}$ is likely to be influenced by $h$. The dependence of $L_{0}^{\downarrow}$ on $h$ and $C$ can be seen in Fig. 8. Considering the varieties of situation which appear in nature, the calculation was done for several values of $C$ and $h$. According to Fig. 8 , it can be seen that for an identical value of $C$, the larger $h$ is, the larger is $\Delta L_{0}^{\downarrow}$. This tendency is particularly prominent in the warm season. For example, $\Delta L_{0}^{\downarrow}$ in the case of $C=0.8$ is about -30 $\mathrm{Wm}^{-2}$ in winter and about $-73 \mathrm{Wm}^{-2}$ in summer for $h=500 \mathrm{~m}$, while it is about $-19 \mathrm{Wm}^{-2}$ to -52 $\mathrm{Wm}^{-2}$ for $h=100 \mathrm{~m}$. This dependence of $\Delta L_{i}^{\downarrow}$ on $h$ is also seen when $C=0.5$; however, in this case, $\Delta L_{0}^{\downarrow}$ is small as compared with that when $C=0.8$. It can be pointed out that the degree of dependence of $\Delta L_{0}^{\downarrow}$ on $h$ when $C=0$ (flat terrain) is small compared to that when $C=0.8$ (basins). This can be explained by the following facts. In the case of flat terrain, the shape of air temperature profiles is determined mainly by the turbulent cooling. As the turbulent cooling is restricted to the layer near the surface when wind is weak, the depth of the cooled air layer over flat terrain is small and increases little with $h$. Thus, the dependence of $\Delta L_{0}^{\downarrow}$ on $h$ is small in 
the case of flat terrain. On the contrary, the depth of cooled air inside a basin and a valley is directly related to $h$, because the cooled air layer is formed mainly by the advection and accumulation of cold air. As the result, the dependence of $\Delta L_{0}^{\downarrow}$ on $h$ is large in a mountainous area.

\subsection{Difference in nocturnal cooling between basins and flat terrain}

Calculated nocturnal cooling for the case of $C=0.8, C=0.5$ and the case of a flat terrain $(C=0)$ are shown in Fig. 9. Before seeing the calculated results, it is necessary to consider the meaning of the two parameters $C$ and $h$ in relation to the various situations in which nocturnal cooling is found in nature. Although it may be necessary to use a parameter such as a "topographical function" (Kondo and Sato, 1984) to represent a complex topographical configuration in nature, we can use parameters $C$ and $h$ to study the nocturnal cooling for several kinds of topographies. When we refer to the case of $C=0.8$, for example, we can signify it as the situation of nocturnal cooling in basins and we can study the

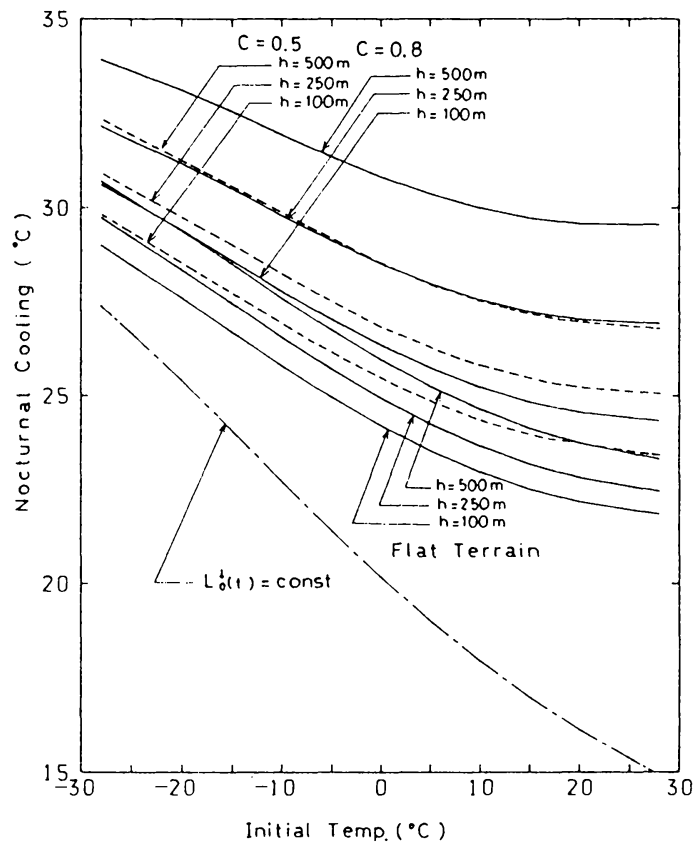

Fig. 9. Calculated nocturnal cooling at flat terrains, basins $(C=0.8)$, the foot of mountains $(C=0.5)$ and the top of mountains ( $L_{0}^{t}=$ const. $)$. effect of the depth of basins on nocturnal cooling by varying $h$ under the condition of the basin's bottom with a fixed diameter. On the other hand, the situation in the case of $C=0.5$ may correspond to the nocturnal cooling at the foot of mountains and it may also satisfy the condition in a very shallow basin ( $h$ is several tens of meters). In the case of nocturnal cooling in valleys, the ratio $C$ may be larger than that for flat terrain, but smaller than that in basins when $h$ is the same. A more detail discussion will be presented later.

According to the calculated results shown in Fig. 9, nocturnal cooling in a deep basin is larger than that in a shallow basin. For example, nocturnal cooling for the range of initial temperatures from $-10^{\circ} \mathrm{C}$ to $25^{\circ} \mathrm{C}$, which are temperatures usually observed at sunset in mid-latitudes, is about $32^{\circ} \mathrm{C}$ to $30^{\circ} \mathrm{C}$ in the case of $C=0.8$ and $h=500 \mathrm{~m}$, while it is $28^{\circ} \mathrm{C}$ to $24^{\circ} \mathrm{C}$ when $C=0.8$ and $h=100 \mathrm{~m}$.

This tendency is also evident in the case of $C=0.5$. That is, the higher the inversion height, the larger is the nocturnal cooling. And it is also true for nocturnal cooling in valleys, that is, the deeper the valley, the larger is the nocturnal cooling.

Regarding the topographies in mountainous areas, we can compare the calculated results for the cases of $C=0.8$ and $C=0.5$ with the observed values shown in Table 1 and Fig. 2. Calculated values of nocturnal cooling are about $23^{\circ} \mathrm{C}$ to $32^{\circ} \mathrm{C}$ over the initial temperature range $25^{\circ} \mathrm{C}$ to $-10^{\circ} \mathrm{C}$ for various values of $h$ and $C$, while observed extreme values are about $19^{\circ} \mathrm{C}$ to $27^{\circ} \mathrm{C}$. Considering the facts mentioned below, we can conclude that this difference in nocturnal cooling is reasonable. This is because, 1) the conditions of the surface used in the calculation are the most favorable ones for the cooling; 2) the calculated values are for the nocturnal cooling on the ground surface, while the observed values are for those at a screen height and obtained from air temperature recorded in one hour time interval; and 3 ) the estimation of air temperature at sunset is somewhat ambiguous, because the sunset time in reality depends on not only latitude and longitude, but also on the topographic configuration. 
For the calculated results in the case of flat terrain, the dependence of nocturnal cooling on $h$ is small. This is due to the fact that $\Delta L_{0}^{\dagger}$
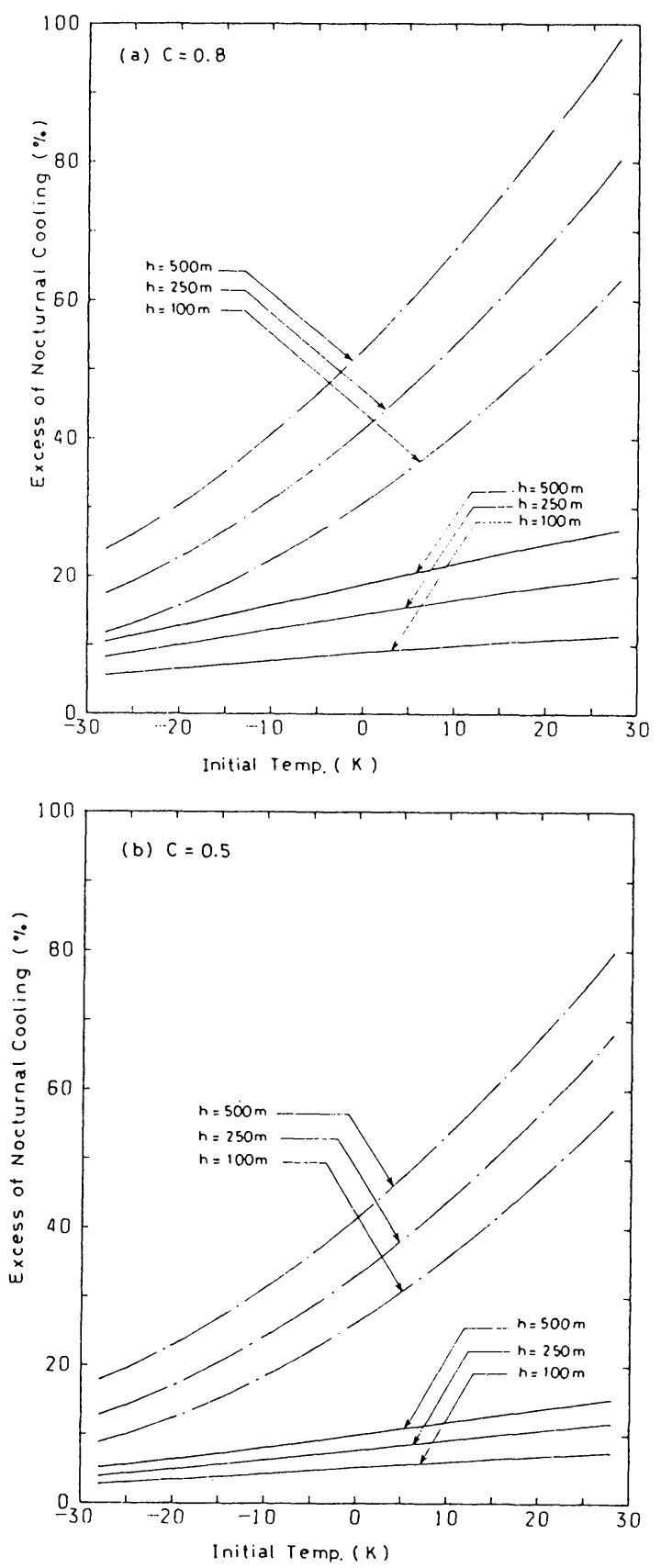

Fig. 10. Excess of nocturnal cooling in basins (a) and the foot of mountains (b). Solid lines represent the excess of nocturnal cooling over that of flat terrain, and chain lines represent the excess of nocturnal cooling over that at the top of mountains. changes little with $h$ as shown in Fig. 8 . Calculated nocturnal cooling is about $22^{\circ} \mathrm{C}$ to $28^{\circ} \mathrm{C}$ over the initial temperature range of $25^{\circ} \mathrm{C}$ to $-10^{\circ} \mathrm{C}$. Observed extreme cooling for an area of plain is about $19^{\circ} \mathrm{C}$ to $23^{\circ} \mathrm{C}$. These differences in nocturnal cooling between calculated values and observed ones are also reasonable for the reasons stated above.

In the case of $L_{0}^{\downarrow}=$ const., which represents nocturnal cooling at the top of a mountain and a hill, cooling is about $15^{\circ} \mathrm{C}$ to $23^{\circ} \mathrm{C}$ when the initial temperature ranges from $25^{\circ} \mathrm{C}$ to $-10^{\circ} \mathrm{C}$.

The difference in nocturnal cooling among topographies is shown in Fig. 10 expressing it as the excess of nocturnal cooling in the case of $C=0.8$ (Fig. 10a) and in the case of $C=0.5$ (Fig. $10 \mathrm{~b})$ relative to nocturnal cooling for flat terrain and the top of mountains. Similar to the dependence of nocturnal cooling on $h$, it is clear that the larger $h$, the larger is the excess of noctournal cooling. When $h=500 \mathrm{~m}$, for example, the excess of nocturnal cooling when $C=0.8$ is about $15 \%$ in the cold season (for example, at an initial temperature $-10^{\circ} \mathrm{C}$ ) and about $25 \%$ in the warm season (for example, at an initial temperature $25^{\circ} \mathrm{C}$ ) as compared with nocturnal cooling for the flat terrain. The difference in nocturnal cooling corresponding to these excess values is about $4^{\circ} \mathrm{C}$ to $6^{\circ} \mathrm{C}$.

On the other hand, the excess of nocturnal cooling when $C=0.5$ is about $10 \%\left(\sim 2^{\circ} \mathrm{C}\right)$ in the cold season and about $15 \%\left(\sim 4^{\circ} \mathrm{C}\right)$ in the warm season, as compared with nocturnal cooling for the flat terrain.

These values are in good agreement with the difference observed in the nocturnal cooling for mountainous areas and areas of plain, except for that in the summer season. According to Table 1, the difference is about $3^{\circ} \mathrm{C}$ in the winter season and about $4^{\circ} \mathrm{C}$ in spring and autumn seasons.

Compared with the nocturnal cooling when $L_{0}^{\downarrow}=$ const., the excess of nocturnal cooling when $C=0.8$ is about $40 \%\left(\sim 9^{\circ} \mathrm{C}\right)$ in the cold season and about $90 \%\left(\sim 15^{\circ} \mathrm{C}\right)$ in the warm season, while it is about $30 \%\left(\sim 7^{\circ} \mathrm{C}\right)$ to $75 \%\left(\sim 12^{\circ} \mathrm{C}\right)$ when $C=0.5$. These results are in good agreement with the analytical results of Kondo (1982). 


\section{Discussion}

\subsection{Relation between $C, h$ and topographic features}

In this study, calculations were performed for $h=100,250,500 \mathrm{~m}$ and for $C=0,0.5,0.8$. Before discussing the calculated results, it may be necessary to clarify the relationship between two parameters $(C$ and $h$ ) and topographic features to relate the calculated results with the nocturnal cooling actually observed at various places.

As the parameter $C$ represents the amount of cooling due to the advection and accumulation, its value may depend on the topographic features. Generally, it can be said that the value $C$ in basins is larger than that at other mountainous regions such as valleys and the foot of mountains. According to Maki et al. (1986), the average value of $C$ under weak wind conditions was found to be about 0.8 in the Akaigawa Basin. On the other hand, it was found to be about 0.5 at the foot of a mountain (Mori et al., 1983). The value $C$ in valleys may lie between these values. Accordingly, we can discuss the difference in nocturnal cooling caused by the topographic difference by using the parameter $C$. On the other hand, $h$ is defined as the temperature inversion height. According to Yoshino (1975), the inversion height $h$ in a mountainous area is closely related to the surrounding mountain height. Thus, if we consider an identical value of $C$ we can discuss the effect of depth of basins or valleys on the noctournal cooling by varying the value of $h$.

Next, it is necessary to clarify the relationship between the parameters $C$ and $h$ because both parameters are not necessarily independent of each other. If we were to state the conclusion first, we would say that the ratio $C$ can be considered to be constant except for small values of $h$. This may be explained as follows. $C$ has been defined as $C=Q X / Q A=Q X /(Q X+Q R+Q H)$. As $Q X$ is directly related with the heat exchange between mountain slope surfaces and air near the surface, $Q X$ is likely to increase with the surrounding mountain height. The term $Q R$ also increases in proportion to $h$ because atmospheric radiative cooling is approximately constant regardless of height. On the other hand, $Q H$ can be neglected as compared with other terms when $h$ is large, because turbulent cooling is restricted to the air layer near the surface. Accordingly, if both $Q X$ and $Q R$ are in proportion to $h$, then the ratio $C$ can be considered to be constant for large $h$. On the contrary, when $h$ is small (several tens of meters), $Q H$ becomes so large that it can no longer be disregarded as compared with $Q X$ or $Q R$. As a result, $C$ takes small values for small $h$, and at the limit, it becomes 0 when $h$ approaches 0 . This same relation between $C$ and $h$ could possibly be applied to the nocturnal cooling in valleys or at the foot of a mountain.

\subsection{Mechanism of nocturnal cooling at various topographies}

We can explain the difference in the mechanism of the nocturnal cooling among topographies by considering the effect of the advection and accumulation of cold air on the amount of downward long wave radiation (Fig. 11). The process of nocturnal cooling at the bottom of a basin is as follows (Magono et al., 1982; Harimaya et al., 1985). After sunset, the air near the surface of the bottom proceeds to cool. On the other hand, a cooling of air also occurs on the slope surface of the surrounding mountains, and this may start a few hours earlier than the cooling at the bottom because of the topographic effect on the real sunset time. Thus, in this stage, which was referred to by Magono et al. (1982) as the second stage of nocturnal cooling, cooled air on the slope flows down to the bottom and cools the air directly. As cooling proceeds, a very stable cold air lake is formed. The depth of this layer is $1 / 4$ to $1 / 5$ of the surrounding mountain height (Yoshino, 1975) and it is almost calm in this layer. Although the downslope cold air contributes a little to the cooling in this layer, it advects and accumulates over the central part of the basin and cools the air above the cold air lake. Then, a deep and cold air layer is formed inside the basin. This deep cold air layer decreases the downward long wave radiation at the bottom of the basin, and thus, the net radiation becomes large. Since the depth of the cold air layer is dependent on the relative height of surrounding mountains, the higher the surrounding mountain height is, the larger is the 

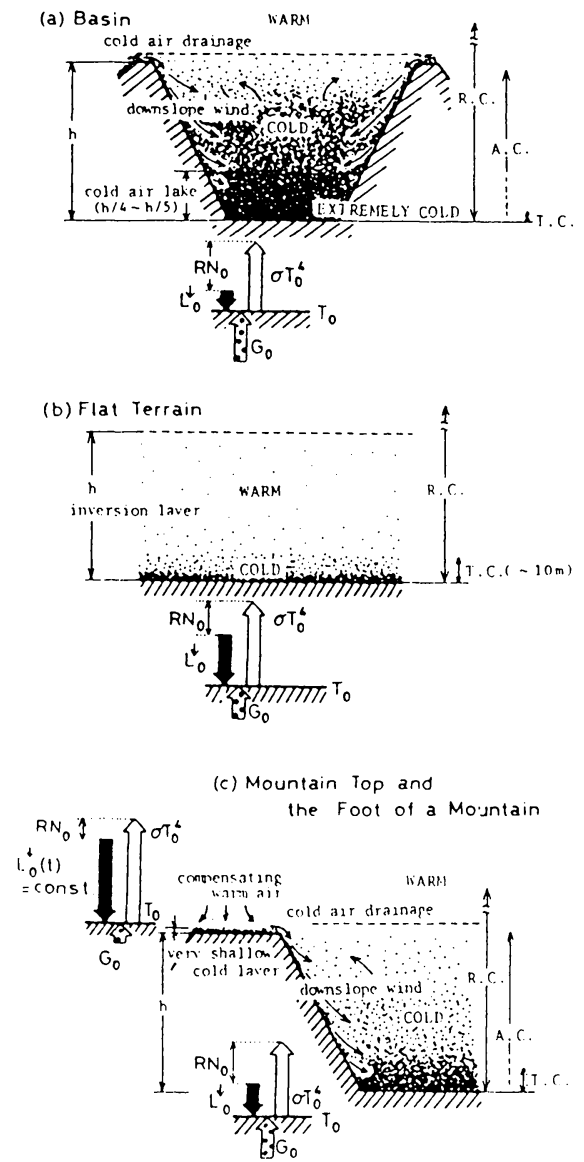

Fig. 11. Schematic pictures explaining the difference in mechanisms of nocturnal cooling at a basin (a), a flat terrain (b), and mountain top and the foot of a mountain (c). Where, A.C. represents horizontal advective cooling, T.C. the turbulent cooling and R.C. the atmospheric radiative cooling.

decrease of $L_{0}^{\downarrow}$ at the bottom. As a result, nocturnal cooling at the surface of the bottom becomes large, especially in deep basins.

In the case of nocturnal cooling on flat terrain, the air layer is also cooled by turbulent and radiative heat transfer. Thus, downward long wave radiation also decreases. However, the depth of the cold air layer is restricted to only a shallow layer near the surface because the depth of the turbulent boundary layer is shallow $(\sim 10 \mathrm{~m})$ under calm wind conditions. The upper part of the inversion layer is cooled only by atmospheric radiative cooling. Then, as has been pointed out by Kondo (1986) through a numerical experiment and by Maki et al. (1986) from observed cooling rate profiles inside a basin, the upper part of the inversion layer over a flat terrain is warmer as compared with that inside a basin. As a result, with the downward long wave radiation being large on flat terrain, the nocturnal cooling at the surface is smaller than that in basins.

On the other hand, in the case of nocturnal cooling at the top of a mountain, the air layer above the surface is cooled by the same mechanism as that which occurs over a flat terrain. However, this cooled air flows down along the slope continuously or intermittently, owing to the balance between the gravitational force and the frictional force. And warm air is supplied from the above air layer to the cooled surface to make up the loss of mass due to the cold air drainage. As a result, with the cooled layer being restricted only in the surface layer close to the ground surface, the amount of long wave radiation decreases only slightly.

In the case of nocturnal cooling at the foot of a mountain, the downslope cold air cools the air over the foot. However, as Kondo and Sato (1984) have pointed out, since the total cooling of the air layer is dependent on the total area of the surrounding mountain slope, the cooling of an air layer over the foot of a mountain is smaller than that inside a basin. This is equivalent to saying that the ratio of advective cooling to actual cooling is smaller than that in a basin. Then, the decrease of $L_{0}^{\downarrow}$ is smaller than that in a basin, while it is larger than that on a flat terrain. As a result, nocturnal cooling at the foot of a mountain is small as compared with that in a basin, while it is large as compared with that for a flat terrain. The nocturnal cooling in valleys may also be explained by the arguments above.

\section{Conclusion}

The advection and accumulation of cold air from surrounding mountain slopes affect the nocturnal cooling in basins. This effect was studied with the use of a one-dimensional numerical model under the conditions of a clear night and calm wind. In the model, cooling due to the advection and accumulation of cold air was parameterized by using the results of heat 
budget analyses (Maki et al., 1986) and assuming the power law profiles of air temperature. The main calculated results are as follows.

When the ratio $C$ of the cooling due to the advection and accumulation of cold air to the actual cooling is 0.8 , which is the situation of nocturnal cooling in basins, then

(1) the nocturnal cooling increases with the surrounding mountain height $h$. When $h=500 \mathrm{~m}$, the nocturnal cooling at the bottom of a basin is about $15 \%$ larger in winter and about $25 \%$ larger in summer than that for flat terrain where horizontal advective cooling does not occur.

(2) The nocturnal cooling in a basin is about $40 \%$ (in winter) to $90 \%$ (in summer) larger than that when $L_{0}^{\downarrow}=$ const., which is the situation of nocturnal cooling at the top of a mountain or a hill.

In the case of $C=0.5$, which is the situation of nocturnal cooling in very shallow basins or piedmont districts where the cooling due to the advection and accumulation of cold air is smaller than that inside basins, then

(3) the nocturnal cooling is about $10 \%$ in winter and about $15 \%$ in summer larger than that at flat terrains, while it is about $30 \%$ (in winter) to $75 \%$ (in summer) larger than the nocturnal cooling at the top of a mountain.

These excesses of nocturnal cooling in basins are due to the decrease in downward long wave radiation $L_{0}^{\downarrow}$ which is caused by the advection and accumulation of cold air inside a basin:

(4) the decrease in the downward long wave radiation $\Delta L_{0}^{\downarrow}$ during 12 hours in a basin depends on $h$ and it is about $30 \mathrm{Wm}^{-2}$ in winter and about $80 \mathrm{Wm}^{-2}$ in summer when $h=500 \mathrm{~m}$, for example. On the other hand, when $C=0.5$, $\Delta L_{0}^{\downarrow}$ is smaller than that in basins, while it is larger than that for flat terrains.

The values calculated for the nocturnal cooling were considered reasonable when compared with the observational data provided by AMeDAS.

\section{Acknowledgements}

The authors would like to thank Professor K. Kikuchi of Hokkaido University for his continuing encouragement and helpful discussions. The authors are also grateful to the late Professor
C. Magono for his helpful discussions. The expense of this work was supported by the Grant-in-Aid for Scientific Research from the Ministry of Education, Science and Culture of Japan.

\section{References}

Anfossi, D., P. Bacci and A. Longhetto, 1976: Forecasting of vertical temperature profiles in the atmosphere during nocturnal radiation inversions from air temperature trend at screen height. Quart. J. Roy. Meteor. Soc., 102, 173-180.

Blackadar, A.K. and H. Tennekes, 1968: Asymptotic similarity in neutral barotropic planetary boundary layers. J. Atmos. Sci., 25, 1015-1020.

Brunt, D., 1932: Notes on radiation in the atmosphere. I. Quart. J. Roy. Meteor. Soc., 58, 389-420.

Delage, Y., 1974: A numerical study of the nocturnal atmospheric boundary layer. Quart. J. Roy. Meteor. Soc., 100, 351-364.

Fleagle, R.G., 1950: Radiation theory of local temperature differences. J. Meteor., 7, 114-120.

Garratt, J.R. and P.A. Brost, 1981: Radiative cooling effects within and above the nocturnal boundary layer. J. Atmos. Sci., 38, 2730-2746.

Groen, P., 1947: Note on the theory of nocturnal radiational cooling of the earth's surface. J. Meteor., 4, 63-66.

Harimaya, T., M. Maki, K. Kikuchi, T. Taniguchi, T. Ohira and M. Yoshihiro, 1985: Observation of nocturnal cooling in Akaigawa Basin, Hokkaido. Geophys. Bull. Hokkaido Univ., 45, 29-41 (in Japanese with English abstract).

Jaeger, J.C., 1945: Note on the effect of wind on nocturnal cooling. Quart. J. Roy. Meteor. Soc., 71, 388-390.

Klöppel, M., G. Stilke and C. Wamser, 1978: Experimental investigations into variations and comparisons with results of simple boundary-layer model. Bound.-Layer Meteor., 15, 135-146.

Knighting, E., 1950: A note on nocturnal cooling. Quart. J. Roy. Meteor. Soc., 76, 173-181.

Kondo, H., 1986: A numerical experiment about the cooling in a basin. J. Meteor. Soc. Japan, 64, 563-574.

Kondo, J., 1971: Effect of radiative heat transfer on profiles of wind, temperature and water vapor in the atmospheric boundary layer. J. Meteor. Soc. Japan, 49, 75-94.

- 1982: Preliminary theoretical study on nocturnal cooling over complex terrain. Tenki, 29, 935-949 (in Japanese).

_, O. Kanechika and Y. Yasuda, 1978: Heat and momentum transfers under strong stability in the atmospheric surface layer. J. Atmos. Sci., 35, 1012-1021.

and T. Sato, 1984: Effect of the topo- 
graphical and ground surface conditions on the nocturnal drainage wind and cooling in mountainous regions (Part 2). Tenki, 31, 747-755 (in Japanese). and H. Yamazawa, 1983: Nocturnal radiational cooling of the earth's surface with the snow-cover, and the extreme minimum airtemperature over Japan. Tenki, 30, 295-302 (in Japanese).

Magono, C., C. Nakamura and Y. Yoshida, 1982: Nocturnal cooling of the Moshiri Basin, Hokkaido in midwinter. J. Meteor. Soc. Japan, 60, 1106-1116.

Maki M. and T. Harimaya, 1984: Spatial variations of nocturnal cooling on Hokkaido island. Geophys. Bull. Hokkaido Univ., 43, 1-15 (in Japanese with English abstract).

_- - and K. Kikuchi, 1986: Heat budget studies on nocturnal cooling in a basin. J. Meteor. Soc. Japan, 64, 727-741.

McClatchey, R.A., R.W. Fenn, J.E.A. Selby, F.E. Volz and J.S. Garing, 1972: Optical properties of the atmosphere. $A F C R L-72.0497$, Air Force Cambridge Research Laboratories, 1-108.

Mori, Y., J. Kondo, K. Shoji, T. Sato, N. Yasuda, S. Haginoya, A. Miura, H. Yamazawa, A. Kawanaka, S. Takahira and E. Abe, 1983: Nocturnal cooling and heat balance at the mountainous district. Tenki, 30, 259-267 (in Japanese).

Nakamura, C. and C. Magono, 1982: The extremely low temperature in Hokkaido, Japan during 1976-77 winter and its numerical simulation. J. Meteor. Soc. Japan, 60, 956-966.

Nieuwstadt, F.T.M., 1980: A rate equation for the inversion height in a nocturnal boundary layer. $J$. Appl. Meteor., 19, 1445-1447.

O'Brien, J.J., 1970: A note on the vertical structure of the eddy exchange coefficient in the planetary boundary layer. J. Atmos. Sci., 27, 1213-1215.

Sasamori, T., 1968: The radiative cooling calculation for application to general circulation experiments. $J$. Appl. Meteor., 7, 721-729.

Sutherland, R.A., 1980: A short-range objective nocturnal temperature forecasting model. J. Appl. Meteor., 19, 247-255.

Toritani, H., 1985: Formation of cold air lake and cold air drainage in the Sugadaira Basin, Nagano Prefecture, Japan. Geographical Rev. of Japan, 58 (Ser. A), 67-79 (in Japanese with English abstract).

Wyngaard, J.C., 1975: Modeling the planetary boundary layer. Extension to the stable case. Bound.-Layer Meteor., 9, 441-460.

Yamada, T., 1979: Prediction of the nocturnal surface inversion height. J. Appl. Meteor., 18, 526-531.

Yamamoto, G., 1952: On a radiation chart. Sci Rep. Tohoku University, Ser. 5, Geophys., 4, 9-23. , 1975: Generalization of the KEYPS formula in diabatic conditions and related discussion on the critical Richardson number. J. Meteor. Soc. Japan, 53, 189-195.

Yoshino, M.M., 1975: Climate in a small area. Univ. Tokyo Press, 549 pp.

Zeman, O., 1979: Parameterization of the dynamics of stable boundary layers and nocturnal jets. J. Atmos. Sci., 36, 792-804.

\title{
盆地における夜間冷却に及ぼす冷気の移流・堆積の効果
}

\author{
真 木 雅 之*・播磨屋 敏 生 \\ (北海道大”学理学部地球物理学教公)
}

\begin{abstract}
盆地において，まわりの山地斜面からの冷気の移流・堆積が地表面の夜間冷却量に及ぼす効果を1次 元の数值モデルを用いて調べた。数值モデルは冷気の移流・堆皘による大気層の冷却を熱収支的なる゙亡場 から考虑したものである。計算絬果によれば，例えば，盆地の深さが $500 \mathrm{~m}$ の場合，風の均い快晴の夜間 に，盆地底での夜閒冷却量は平坦地に比べ約 $15 \%$ (冬期) から約25\%（夏期）大きくなり，山頂や丘陵 頂部に比べ約 $40 \%$ (冬期) から約 $90 \%$ (夏期) 大きくなる。これは, 盆地のようにまわりを山で沮まれ たところでは山地斜洦からの冷気が盆地中央部上空へ移流・堆積するために, 湓地低での下向さの大気 放射量が小さくなり，地表面の放射冷却を強めるためである。この泠気の移流・唯積の効果は深い盆地 ほど顕著である。移流による大気層の冷却が盆地に比べて小さい山麓の地表面冷却量は盆地に比べて小 さくなるが，平坦地に比べて約10\%（冬期）から約15\%（夏期）大きく,山頂や丘陵頂部に比べて約 30\% (冬期) から約75\%（夏期）大さくなる。計算された結果はAMeDASで観測された結果と比較して 妥当なものであった。
\end{abstract}

*現在：国方䏚災科学技術センター 